\title{
Mapeamento do Uso da Terra e Identificação de Conflitos Legais em Áreas de Preservação Permanente Utilizando SIG
}

\author{
Mapping of land use and identification of legal conflicts in areas of permanent preservation \\ in the using SIG
}

\author{
Rodrigo Da Cruz' \\ Mastrângello Enivar Lanzanovall \\ Ramiro Pereira Bisognin ${ }^{\prime \prime \prime}$
}

\section{Resumo}

A Lei Federal no. 12.651/2012 define APPs como áreas protegidas, cobertas ou não por vegetação nativa, com a finalidade de preservar os recursos hídricos, a biodiversidade, proteger o solo e assegurar o bem-estar das populações humanas, podendo ser urbanas ou rurais. Portanto, o conhecimento das áreas destinadas a preservação ambiental é fundamental para orientar a utilização racional do território. Por esse motivo, no presente estudo se objetivou identificar e mapear a ocorrência de conflitos no uso da terra em APPs de recursos hídricos urbanos no município de Giruá/RS. Para tanto, foram utilizadas imagens de satélite processadas no software ArcGIS ${ }^{\circ}$ 10.6. A delimitação das APPs foi realizada conforme art. $4^{\circ}$ da Lei Federal no․ 12.651/2012. A cobertura da terra foi classificada em a) áreas urbanizadas; b) áreas antrópicas agrícolas; c) nascentes e cursos d'água; d) APPs e; e) áreas de vegetação natural. Como resultado identificou-se $8,55 \mathrm{~km}^{2}$ de zona urbana, ocupada em $59,25 \%$ por áreas urbanizadas, $27,5 \%$ por áreas antrópicas agrícolas, $12,34 \%$ por vegetação natural. As APPs ocupam 4,36 \% do território urbano. Verificou-se que $29,93 \%$ das APPs possuem uso conflitivo. Em razão disso indica-se a recuperação das áreas que estão em desacordo com a legislação ambiental.

Palavras-chave: Código florestal; sistema de informação geográfica; proteção ambiental; mata ciliar.

\section{Abstract}

Federal Law No. 12.651/2012 defines PPAs as protected areas, covered or not by native vegetation, with the goal of preserving water resources, biodiversity, protecting the soil and ensuring the well-being of human populations, which can be urban or rural. Therefore, the knowledge of areas destined to environmental preservation is fundamental to guide the rational use of the territory. For this reason, this study aimed to identify and map the occurrence of land use conflicts in urban water resource PPAs in the municipality of Giruá/RS. For this purpose, satellite images processed in the ArcGIS ${ }^{\circledast} 10.6$ software were used. The delimitation of the PPAs was performed according to art. 4th Federal Law n․ 12.651/2012. Land cover was classified in a) urbanized areas; b) Agricultural anthropic areas; c) Springs and watercourses; d) PPAs; e) Areas of natural vegetation. As a result it was identified $8.55 \mathrm{~km}^{2}$ of urban area, occupied in $59.25 \%$ by urbanized areas, $27.5 \%$ by agricultural anthropic areas, $12.34 \%$ by natural vegetation. The PPAs occupy $4.36 \%$ of the urban territory. It was found that $29.93 \%$ of the APPs have conflicting use. As a result, the recovery of the area that are in disagreement with environmental legislation is indicated.

Keywords: Forestry code; geographic information systems; environmental protection; ciliary forest. 


\section{Introdução}

As Áreas de Preservação Permanente (APPs) são locais do território que desempenham função ambiental primordial na conservação dos recursos naturais. Conforme dispõe o Código Florestal, Lei Federal nº. 12.651 de maio de 2012, as APPs são definidas como áreas protegidas, cobertas ou não por vegetação nativa, com função ambiental de preservar os recursos hídricos, a paisagem, a estabilidade geológica e a biodiversidade, facilitar o fluxo gênico de fauna e flora, proteger o solo e assegurar o bem-estar das populações humanas. Consistem em espaços territoriais legalmente protegidos, ambientalmente frágeis e vulneráveis, podendo ser públicas ou privadas, urbanas ou rurais (BRASIL, 2012).

As APPs constituem um instrumento importante para proteção e recuperação da qualidade hídrica, em especial no meio urbano por concentrar fontes de perturbação e alteração do uso da terra decorrentes das atividades antrópicas desenvolvidas as margens de nascentes e cursos d'água (BRESSANE et al., 2016). A maioria dos cursos d'água localizados no meio urbano sofre um processo histórico de degradação e isolamento, e sua presença é, por vezes relacionada à incômodos, como mau cheiro, obstáculo à circulação, e ameaça de inundações (MACEDO, 2011).

O crescimento populacional e a ocupação desordenada em áreas urbanas têm desencadeado problemas sociais e desequilíbrios ecológicos (BORGES, 2011). De acordo com a Empresa Brasileira de Pesquisa Agropecuária (EMBRAPA, 2017), as áreas urbanas brasileiras ocupam $0,63 \%$ do território nacional, mas é ocupada por cerca de 177,5 milhões de pessoas. Segundo Instituto Brasileiro de Geografia e Estatística (IBGE), no ano de 1960 o Brasil apresentava população de 70,9 milhões de pessoas, sendo que $45,2 \%$ residiam em áreas urbanas. Atualmente o país registra a soma de 208,4 milhões de pessoas, com cerca de $85 \%$ da população residindo nas cidades (IBGE, 2018). Essa rápida e intensa transformação no processo de configuração territorial do Brasil exige uma reorientação nas políticas públicas e faz surgir discussões sobre o desenvolvimento de cidades sustentáveis do ponto de vista ambiental, social e econômico, e as APPs assumem grande importância no desenvolvimento sustentável, pois sua manutenção proporciona valorização da paisagem do patrimônio natural e construído, melhoria no conforto microclimático, conservação do solo e biodiversidade (SEPE et al., 2014).

Os estudos realizados para diagnosticar as condições ambientais têm colaborado no planejamento das ações governamentais, facilitando as tomadas de decisões, servindo como instrumento de alerta e orientação para os efeitos intensivos de uso da terra (MOREIRA, 2009). Reis et al, (2009) ressaltam que a falta de conhecimento a respeito da correta localização das APPs é a principal causa do descumprimento da legislação. No entanto, o monitoramento das APPs tem sido um grande desafio, pois os critérios de delimitação com base em métodos topográficos exigem o envolvimento de pessoal especializado e de informações obtidas em campo. Porém o uso de Sistema de Informações Geográficas (SIG) tem se tornado imprescindível para estudos ambientais, pois permite o processamento de imagens de satélite e dados cartográficos (CARDOSO; AQUINO, 2013). Esses dados, combinados com informações específicas para a caracterização da cobertura e uso da terra como dados de infraestrutura, crescimento urbano e diretrizes legais, geram um diagnóstico com informações geograficamente referenciadas. (CÂMARA, 1998; OLIVEIRA, 2002). Nunes et al., (2015) destacam que os diagnósticos de conflitos de uso da terra, através de técnicas de geoprocessamento, servem como subsídio para os órgãos públicos na tomada de decisões em eventuais intervenções em APPs, principalmente, tratando-se de atividades de recuperação, monitoramento de desmatamentos e estudos de diversidade de flora e a fauna. Do mesmo modo Pinto e Rossete (2013), acrescentam que a identificação das áreas de conflitos no uso da terra em APPs é um importante instrumento para promover o manejo adequado dos recursos naturais em especial da água. Além disso Eugenio (2010) acrescenta a necessidade de avaliação "in loco" das condições das APPs, pois a ocorrência de fragmentos florestais nas faixas marginais de cursos d'água sob a pressão da expansão urbana e atividades agrícolas pode apresentar significativo grau de degradação em seu interior, que podem não ser visualizadas na interpretação pela imagem de satélite.

Estudos tem sido desenvolvidos para avaliar o uso e cobertura da terra e o uso conflitivo em APPs, considerando geralmente como unidade de mapeamento as bacias hidrográficas.

Osco et al. (2016) em estudo com objetivo de mapear as feições naturais e delimitar as APPs da bacia hidrográfica do alto curso do Rio Santo Anastácio, na região de Presidente Prudente/SP, verificaram que 74,24\% das APPs não possuíam vegetação arbórea. Pollo et al. (2014) avaliaram o uso e ocupação da terra das APPs segundo o Código Florestal e seus conflitos de uso, com a utilização de SIG na bacia hidrográfica do Ribeirão Paraíso, município de São Manuel/SP, e constataram que 80,13\% das APPs apresentavam uso conflitivo, com base na legislação. Avaliando o uso conflitivo das APPs em áreas urbanas, Caixeta (2009) desenvolveu um estudo na microbacia do Ribeirão Anicuns - Goiânia/GO, apresentando um exemplo de áreas protegidas pela legislação ambiental que estão urbanizadas (em conflito) com o auxílio de ferramentas de geoprocessamento e imagem de satélite processadas no software ArcGIS ${ }^{\circledast}$, utilizando a base cartográfica disponível no município.

De acordo com a lei orgânica do município de Giruá/RS, é de competência do município, planejar o uso e ocupação da terra, especialmente na zona urbana, e para adequada gestão territorial, a fim de orientar a utilização racional do espaço contribuindo na conservação dos recursos naturais. Além disso, o inciso VI, art. 70 do Plano Diretor, Lei Municipal nº. 4.951 de novembro de 2013, dispõe como ações administrativas do Município promover o desenvolvimento de estudos e pesquisas direcionados à proteção e à gestão ambiental, 
divulgando os resultados obtidos. Nesse aspecto o art. 78 da referida Lei, abordando a gestão municipal do meio ambiente, estabelece que deverão ser instituídos mapas de recursos hídricos do município, indicando ribeirões, córregos, rios, nascentes e represas, com suas faixas de preservação permanente, considerando que tais informações servirão de subsídio para futura elaboração do Zoneamento Ambiental do Município (GIRUÁ, 2013). Portanto, a abordagem deste estudo vem ao encontro da necessidade do município em dispor de informações sobre questões de uso e cobertura da terra com ênfase nas APPs, considerando a legislação municipal, e integrando as informações cartográficas definidas pelo plano diretor ao Sistema de Informação Geográfica desenvolvido para o estudo.

Nesse Sentido, o presente estudo objetivou identificar e mapear a ocorrência de conflitos no uso da terra em APPs urbanas do município de Giruá/RS.

\section{Material e Métodos}

\subsection{Caracterização da área de estudo}

O estudo foi realizado na área urbana do município de Giruá, localizado na região noroeste do Estado do Rio Grande do Sul, sob as coordenadas $54^{\circ} 20^{\prime} 57,50^{\prime \prime} \mathrm{W}$ $28^{\circ} 1^{\prime} 47,98^{\prime \prime}$, na bacia do rio Uruguai. O município apresenta uma altitude média de $420 \mathrm{~m}$. O clima, segundo a classificação de Koppen, é subtropical úmido, com temperatura média anual de $19^{\circ} \mathrm{C}$. Apresenta área territorial de $855 \mathrm{~km}^{2}$ e população estimada de 16.151 habitantes (IBGE, 2018). A área urbana do município corresponde a $8,55 \mathrm{~km}^{2}$ e caracteriza-se pela localização de nascentes e cursos d'água integrantes da bacia hidrográfica dos Rios Turvo, Santo Cristo e Santa Rosa, localizadas conforme o Sistema Estadual de Recursos Hídricos, na bacia hidrográfica U 30 , região hidrográfica do rio Uruguai.

\subsection{Base de dados para elaboração dos mapas}

As imagens utilizadas para o estudo foram obtidas do satélite Landsat-8 sensor OLI com resolução espacial de 30 metros, e $15 \mathrm{~m}$ para banda 8 pancromática, as bandas 4-6-7 correspondem as faixas de intervalo no espectro eletromagnético do visível $(0,64-0,67 \mu \mathrm{m})$ e infravermelho $(1,57-2,29 \mu \mathrm{m})$, coletadas em 15 de fevereiro de 2018 e disponibilizadas pelo Instituto Nacional de Pesquisas Espaciais (INPE). Os dados cartográficos foram obtidos junto ao município em formato DWG, contendo a área urbana e a face dos logradouros entre outras informações da área de estudo. A partir desses materiais foram elaboradas os seguintes mapas: mapa de classificação de uso e ocupação da terra urbana, contendo as classes de uso da terra; mapa das APPs urbanas; e o mapa de uso e ocupação da terra nas APPs. O tratamento e análise dos dados foi realizado por meio do software ArcGIS ${ }^{\circ}$, versão 10.6.

\subsection{Rede hidrográfica}

A rede hidrográfica é composta por cursos d'água e nascentes. Para gerar a rede hidrográfica urbana de Giruá utilizou-se a imagem (SRTM) com resolução de 30 m, denominada Modelo Digital de Elevação - MDE, que permite gerar dados de hidrografia e elevação do relevo (altimetria). Essa imagem foi processada com uso da ferramenta "hidrology" disponível no módulo ArcToolbox do software ArcGIS ${ }^{\circ}$ 10.6. As nascentes foram marcadas no início de cada curso d'água, posteriormente realizou-se a busca "in loco", utilizando aplicativo Avenza Maps, para atestar a localização e registro das coordenadas das nascentes, conforme descrito no item 2.7 de avaliação em campo.

\subsection{Delimitação das APPs no entorno de nascentes e ao longo da faixa marginal dos cursos d'água}

Nessa etapa foi utilizada a base de dados correspondente aos cursos d'água e pontos relacionados às nascentes. As APPs foram delimitadas conforme art. 4 da Lei Federal no. 12.651/2012 (Brasil, 2012). Para tanto, seguiu-se a metodologia empregada por Peluzio et al. (2010), utilizando o comando "buffer", disponível no módulo de geoprocessamento do software ArcGIS" 10.6. As APPs do entorno das nascentes foram delimitadas considerando um raio de preservação de 50 metros, e para as APPs dos cursos d'água, que apresentam menos de 10 $\mathrm{m}$ de largura, característica de início da rede de drenagem, delimitou-se $30 \mathrm{~m}$ de faixa para ambas as margens.

\subsection{Mapeamento da cobertura e uso da terra}

O mapa de uso e ocupação da terra foi elaborado com a composição das bandas 7-6-4 RGB, usadas para análises urbanas. Após a composição foi realizado a fusão com a banda 8 - pancromática, para melhoria da resolução, com uso da ferramenta "image analysis" disponível no software ArcGIS ${ }^{\circledR}$ 10.6. A classificação foi realizado conforme metodologia empregada por Gasparini et al. (2013) utilizando o método de classificação supervisionada por mínima distância, em que se toma como referência, para cada classe, um ponto no espaço multidimensional definido pela média estatística de cada banda espectral considerada. O algoritmo associa cada pixel desconhecido à classe cuja média está mais próxima. Cada pixel dentro e fora das áreas de treinamento é avaliado e assinalado à classe à qual este tem a maior probabilidade de pertencer. Esse método também é chamado de classificação pixel a pixel, é realizado com base na interação da radiação com a superfície dos objetos. Os algoritmos desses métodos analisam a característica espectral de cada pixel da imagem e os categoriza dentro de uma classe específica por meio de métodos estatísticos (SOARES, 2015). Com uso da ferramenta "image classification" definiu-se amostras com características de pixel das áreas correspondentes as classes temáticas de estudo e a ferramenta realizou a 
classificação da cobertura da terra para a área de estudo. Posteriormente realizou-se a consolidação da classificação, ajustes e edição dos mapas com uso de ferramentas de geoprocessamento disponíveis no $\operatorname{ArcGIS}^{\circledR}$ 10.6. Os mapas foram elaborados na escala 1:40.000.

As classes do uso da terra foram definidas conforme Manual Técnico de Uso e cobertura da Terra do IBGE (2013), considerando a finalidade do estudo, compreendendo as seguintes classes temáticas:

- Áreas urbanizadas: compreende áreas de uso intensivo, estruturadas por edificações e sistema viário, onde predominam as superfícies artificiais com construções, edificações considerando também a arborização urbana.

- Áreas antrópicas agrícolas: encontram-se inseridas nesta categoria as lavouras temporárias, pastagens, silvicultura e áreas caracterizadas agrícolas, incluindo terras cultivadas ou em pousio.

- Áreas de vegetação natural: abrange capoeira, matas ciliares e cobertura vegetal com características naturais, mesmo vegetação primária sem extrato arbóreo estruturado.

- Recursos hídricos: agrupa cursos d'água e nascentes.

\subsection{Análise de conflito no uso da terra}

Utilizou-se a base de dados gerados no mapa de cobertura e uso da terra e o mapa com as APPs, sobrepondo a cobertura e uso da terra em relação as APPs delimitadas. Para tanto, utilizou-se a ferramenta de geoprocessamento "union", disponível no módulo ArcToolbox do software ArcGIS $^{\infty}$ 10.6. Verificou-se que a camada vetorial APP foi sobreposta pela camada vetorial áreas urbanizadas e áreas antrópicas agrícolas, delimitando-se dessa forma a cobertura e uso da terra no interior das APPs, sendo considerado essas áreas em conflito no uso da terra. Em seguida, com o uso do comando "clip" do software ArcGIS ${ }^{\oplus} 10.6$, extraiu-se essas áreas para análise e cálculo, evitando sobreposição.

\subsection{Avaliação em campo}

Em complementação ao trabalho foram realizadas visitas em campo durante o mês de Novembro de 2018, com o objetivo de observar as classes de uso da terra bem como validar a interpretação realizada no processamento digital das imagens de satélite. Para essa etapa foi utilizado o aplicativo Avenza Maps instalado em aparelho Smartphone. Esse aplicativo é uma solução tecnológica desenvolvida pela Empresa Canadense Avenza Systems, que permite carregar e usar os próprios mapas georreferenciados, elaborados em ambiente SIG, possibilitando a navegação off-line com sinal de GPS do dispositivo móvel. Com ferramentas cartográficas dedicadas a coleta e registro de coordenadas, esse aplicativo permite rastrear a localização, marcar pontos e percursos além de outros dados em campo.

Para essa etapa realizou-se a importação, em formato PDF, do mapa de Cobertura e Uso da Terra nas APPs urbanas do município de Giruá/RS, em seguida iniciou-se o deslocamento em campo nas APPs e a navegação com o aplicativo Avenza Maps, foram registradas as coordenadas das nascentes, proporcionando maior precisão e confiabilidade nas informações mapeadas. Além do registro das nascentes foram verificadas se as classes de uso das APPs realizadas no processamento digital das imagens de satélite eram condizente com a realidade "in loco”, da mesma forma ao realizar o percurso nas APPs o aplicativo indicava o deslocamento e a localização no mapa permitindo verificar se a classe de uso da terra, por exemplo área urbanizada, era condizente com a classe de uso em campo. Após essa etapa realizou-se alguns ajustes pontuais nos mapas elaborados, para que a representação fosse adequada a realidade. Além disso realizou-se o registro fotográfico das classes de cobertura e uso da terra nas APPs que apresentaram uso conflitivo, com uso de câmera digital Sony Cyber-Shot, modelo DSC-W710, resolução de 16.1 megapixels.

\section{Resultados e Discussão}

\subsection{Cobertura e uso da terra urbana}

Os resultados obtidos com a classificação temática exibem a representação da cobertura e uso da zona urbana no distrito sede do município de Giruá/RS (Figura 1).

A Tabela 1 apresenta a classificação das áreas de acordo com o uso da terra incluindo a área do Parque Urbano Elso Pilau.

Como resultados em análise dos mapas elaborados, constatou-se que o perímetro urbano é de $8,55 \mathrm{~km}^{2}(855,2$ ha) conforme representado na Figura 1. Avaliando a distribuição espacial dos usos da terra, percebe-se que áreas urbanizadas é a principal classe em cobertura e uso da terra, ocupando 5,06 km² (506 ha) do território urbano estudado. As áreas antrópicas agrícolas, representaram o segundo maior uso da terra do território urbano, 2,35 km² (235 hectares). Conforme o Plano de Desenvolvimento Físico e Urbano do Município de Giruá/RS, Lei Municipal nº 4.953, de novembro de 2013, estabelece no Art. 7 que as atividades agrícolas e pecuárias já existentes no Perímetro Urbano podem continuar a ser praticadas, sendo vetado o aumento ou criação de novas atividades sem a aprovação do poder público, considerando dessa forma que as atividades agropecuárias consolidadas desenvolvidas na zona urbana são permitidas, desde que respeitadas as restrições estabelecidas pelo poder público.

As áreas de vegetação natural correspondem a 1,05 $\mathrm{Km}^{2}$ (105 ha) que somadas a área do Parque Urbano Elso Pilau $\left(0,08 \mathrm{~km}^{2}\right)$ equivalem a cerca de 113 ha. Ressalta-se que as APPs na área do Parque Urbano Elso Pilau não apresentam uso conflitivo, devido as situações previstas na legislação pertinente ao regime jurídico das APPs. Como regra geral, as APPs são caracterizadas pela intocabilidade e vedação de uso econômico direto (AZEVEDO; OLIVEIRA, 2014). Porém conforme dispõe Art. 8 Lei Federal no 12.651/2012, excepcionalmente, admite-se a utilização de APPs em casos de utilidade 
Figura 1 - Cobertura e uso da terra urbana do município de Giruá/RS

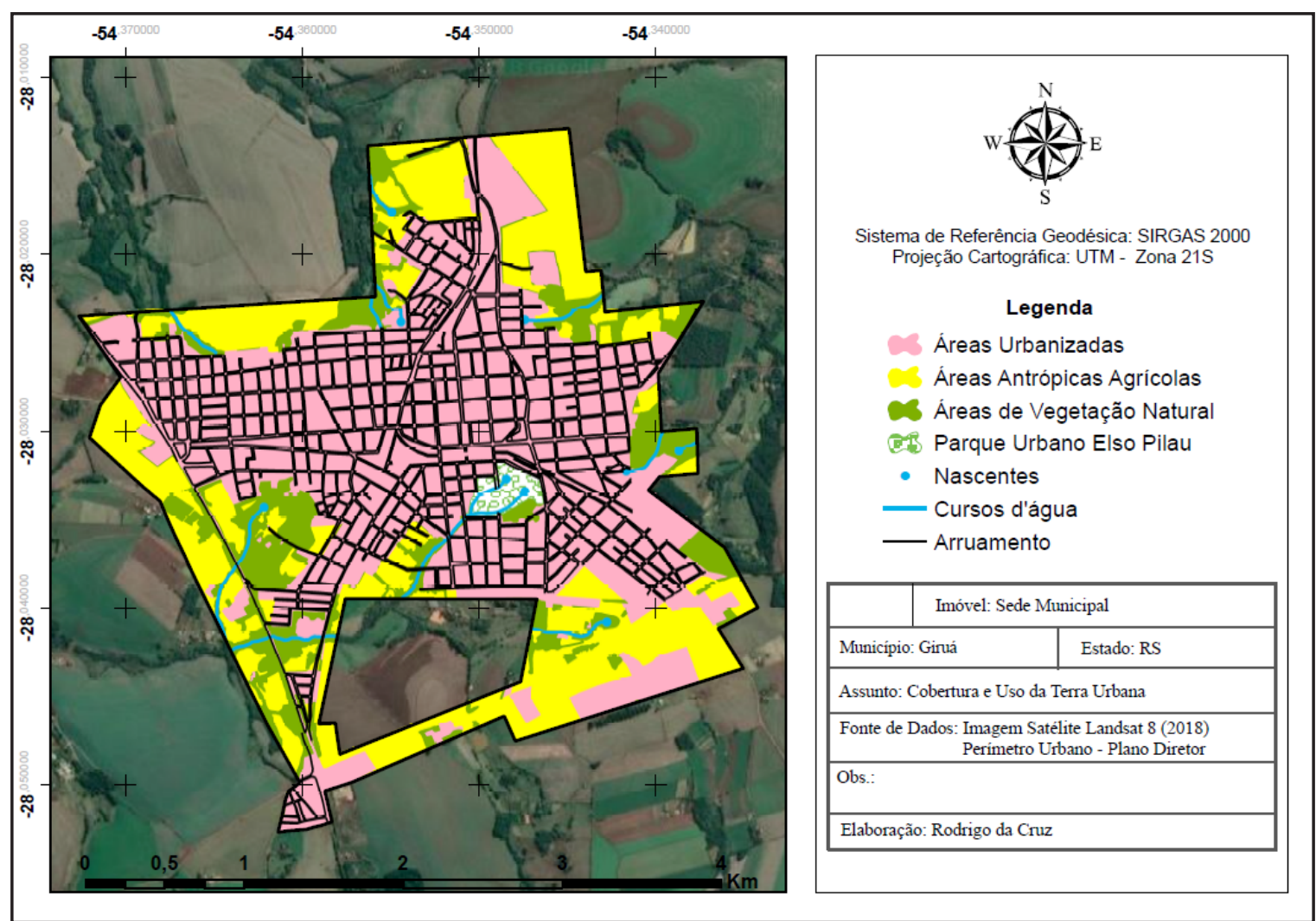

Tabela 1 - Porcentagem de ocorrência de cada classe de uso da terra urbana do município de Giruá/RS.

\begin{tabular}{lccc}
\hline Classe & Área $\left(\mathrm{Km}^{2}\right)$ & Área (ha) & $\%$ \\
\hline Áreas Urbanizadas & 5,06 & 506,68 & 59,25 \\
Áreas Antrópicas Agrícolas & 2,35 & 235,17 & 27,50 \\
Áreas de Vegetação Natural & 1,05 & 105,54 & 12,34 \\
Parque Urbano Elso Pilau & 0,08 & 7,81 & 0,91 \\
TOTAL & 8,55 & 855,2 & 100 \\
\hline
\end{tabular}

pública, de interesse social, e baixo impacto ambiental. Portanto a área do Parque Urbano Elso Pilau se caracteriza como uma ação de interesse Social, de acordo com o Art. 3 da Lei Federal no 12.651/2012 que estabelece como ações de interesse social a implantação de infraestrutura pública destinada a esportes, lazer e atividades educacionais e culturais ao ar livre em áreas urbanas e rurais consolidadas de acordo com as condições estabelecidas em Lei. Destacamos que não faz parte desse trabalho analisar se o uso do Parque está de acordo com a legislação.

Referente a área ocupada pelos recursos hídricos (nascente e cursos d'água), essa classe apresentou pouca representatividade no território, devido as característica de início de rede de drenagem com nascentes e cursos d'água que possuem baixa vazão.

\section{2 Áreas de Preservação Permanentes urbanas}

Dentre as categorias possíveis de APPs constantes na legislação, foram identificadas somente APPs resultantes da presença de cursos d'água e nascentes, não existindo enquadramento nas categorias de topos de morro e encostas, tendo em vista as características geomorfológicas de relevo suave de Giruá, com variação de altitude na zona urbana de 370 à $430 \mathrm{~m}$.

As APPs compreendem 37,35 ha, correspondendo a $4,36 \%$ da área total urbana do município $(855,2$ ha). A Figura 2 apresenta a delimitação das APPs urbanas.

O percentual de cobertura territorial pelas APPs na área urbana do município de Giruá/RS é demostrado na Tabela 2.

As APPs predominantes são decorrentes dos cursos 
Figura 2 - APPs urbanas do município de Giruá/RS.

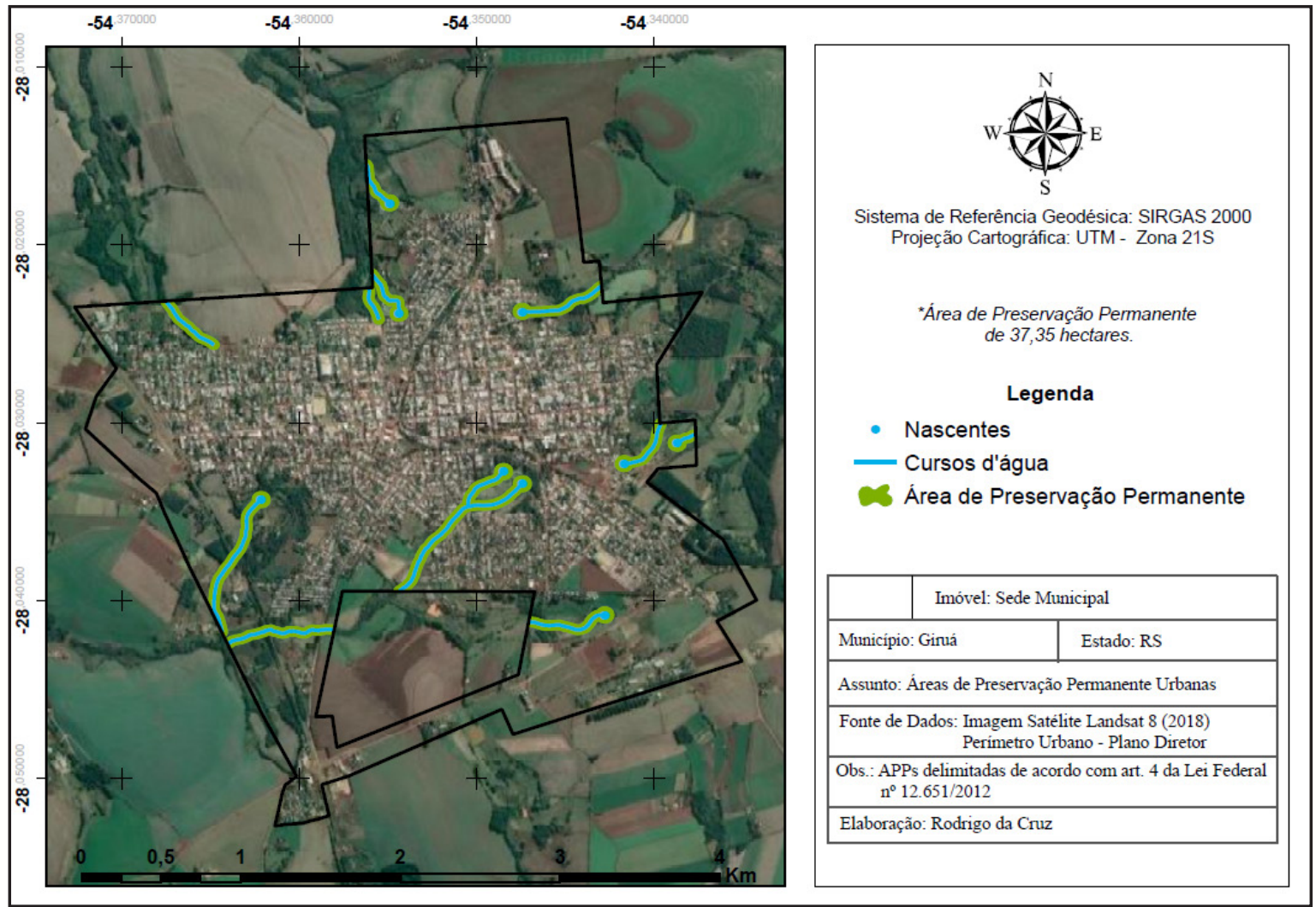

Tabela 2 - Área ocupada pelas APPs no município de Giruá/RS.

\begin{tabular}{|c|c|c|c|c|}
\hline APPs & Característica & Área (ha) & $\begin{array}{c}\text { \% da área em } \\
\text { relação a área total } \\
\text { de APPs }\end{array}$ & $\begin{array}{l}\text { \% da área em } \\
\text { relação a área de } \\
\text { estudo }\end{array}$ \\
\hline Nascentes & Raio de 50 m & 7,05 & 18,9 & 0,82 \\
\hline Cursos d'água & Buffer de 30 m & 30,3 & 81,1 & 3,54 \\
\hline TOTAL & Sem sobreposições & 37,35 & 100 & 4,36 \\
\hline
\end{tabular}

d'água correspondendo a $81,1 \%$, enquanto as de nascentes representam $18,9 \%$ do total identificado na área urbana.

Para proteção de áreas prioritárias de interesse ambiental, o município de Giruá promulgou a Lei Municipal n. 4.954, de novembro de 2013, que dispõe sobre o parcelamento do solo urbano, e estabelece em seu Art. 23 que não será permitido o parcelamento do solo para fins urbanos e em condomínios por unidades autônomas em florestas e demais formas de vegetação natural situadas ao longo de rio ou qualquer curso de água, nascentes, mesmo nos chamados "olhos d'água, seja qual for a situação topográfica”, sendo ao longo das águas correntes e dormentes obrigatória a reserva de uma faixa "não edificável”, respeitando a legislação ambiental pertinente as Áreas de Preservação Permanente (GIRUÁ, 2013).

Segundo Machado (2006) a preservação das APPs é um ato de "inteligência social" pois permite a adaptação às condições ambientais desses locais, sendo característica essencial para o desenvolvimento de cidades sustentáveis.

Para Andrade e Oliveira (2007) as APPs são espaços territoriais especialmente protegidos em razão da manifesta e relevante função socioambiental, constitui-se em condicionante à efetivação do direito fundamental ao meio ambiente ecologicamente equilibrado bem de uso comum do povo e essencial à sadia qualidade de vida, reconhecido na Constituição Federal Brasileira, por meio do art. 225 como direito humano fundamental e impõe ao poder público e à coletividade o dever de defende-lo e preservá-lo para as presentes e futuras gerações.

\subsection{Cobertura e uso da terra nas APPs urbanas}

A cobertura e uso da terra nas APPs é demonstrado na Figura 3.

A porcentagem de ocorrência de cada classe de uso nas APPs é apresentada na Tabela 3.

O cálculo das áreas das classes de Cobertura e Uso da Terra no interior das APPs comprovam quantitativamente o uso conflitivo em determinadas áreas. Verifica- 
Figura 3 - Cobertura e Uso da Terra nas APPs urbanas do município de Giruá/RS.

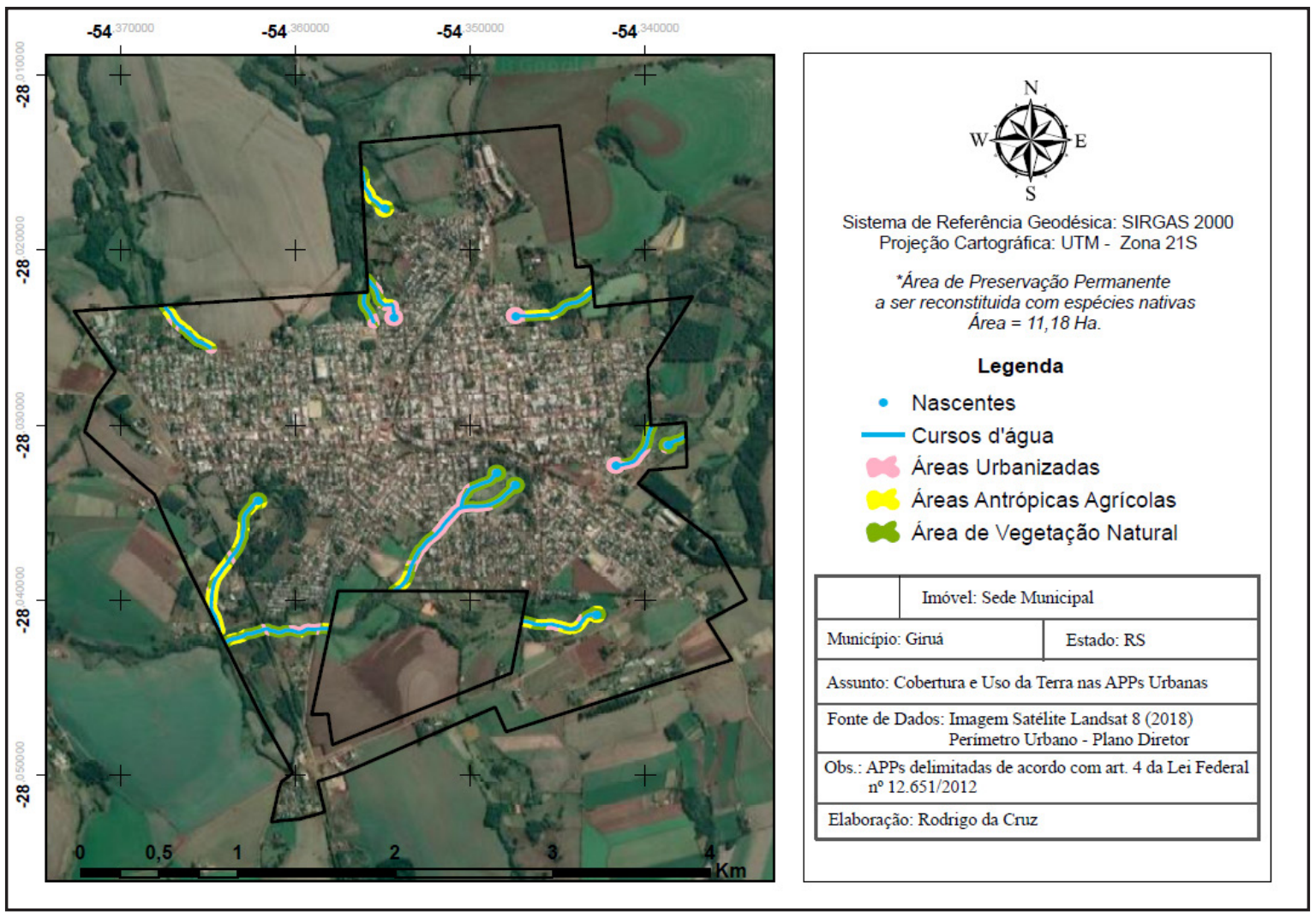

Tabela 3 - Porcentagem de ocorrência de cada classe de uso da terra no interior das APPs.

\begin{tabular}{lcc}
\hline Classe & Área (ha) & $\begin{array}{c}\text { \% de Cobertura e Uso da } \\
\text { Terra nas APPs }\end{array}$ \\
\hline Áreas Urbanizadas & 6,11 & 16,36 \\
Áreas Antrópicas Agrícolas & 5,07 & 13,57 \\
Áreas de Vegetação Natural & 26,17 & 70,07 \\
TOTAL & 37,35 & 100 \\
\hline
\end{tabular}

-se que as APPs encontram-se parcialmente ocupadas pelas áreas urbanizadas $(16,36 \%)$, e $13,57 \%$ por áreas antrópicas agrícolas, evidenciando o não cumprimento das legislações ambientais nessas áreas. Seguindo os parâmetros impostos pela Lei Federal no $12.651 / 2012$, as APPs deveriam possuir o total de 37,35 ha, mas a representação de vegetação natural nessas áreas foi de 26,17 ha. A classe de vegetação natural concentra $70,07 \%$ das APPs. Constatou-se que 11,18 ha das APPs no perímetro urbano apresentam uso em desacordo com a legislação.

Estudos com a finalidade de identificar conflitos no uso da terra em APPs tem sido realizados. Destacamos na sequência alguns trabalhos, como o estudo de Pinto e Rossete (2013) com o objetivo de empregar metodologias e técnicas de geoprocessamento para o mapeamento dos conflitos ambientais em APPs na microbacia hidrográfica do córrego Capitão Décio, Nova Xavantina/MT. Os autores constataram que $88,53 \%$ das APPs estão cobertas por vegetação nativa e que apenas $11,47 \%$ das áreas destinadas à preservação possuem uso indevido da terra, sendo considerada pelos autores como em ótimo estado de conservação. Da mesma forma Mensah et al. (2018) mapearam as APPs na bacia hidrográfica do Ribeirão do Rosário em Delfim Moreira/MG, e identificaram que o uso e cobertura das APPs estava distribuído em $61 \%$ de remanescente florestal, 35\% agropecuária e 4\% área urbana.

Ao classificarem o uso e ocupação das APPs no município de Paulínia/SP, conforme sua adequação com a legislação, Campos e Matias (2012) verificaram que 8,3 $\mathrm{km}^{2}(71,55 \%)$ estavam de acordo com o estabelecido, enquanto $3,3 \mathrm{~km}^{2}(28,45 \%)$ possuíam uso e ocupação em desacordo com a legislação. Os autores destacam que apesar da porcentagem de APPs não preservadas não ser um valor muito alto, deve-se considerar que há um quadro crescente de ocupação dessas áreas e que elas possuem influência sobre uma área muito maior do que a sua própria. Além disso, os autores identificaram que as margens dos cursos hídricos na área urbana, passaram pela implantação de loteamentos que causaram o 
soterramento de diversas nascentes sendo indevidamente ocupadas por casas, chácaras e até industrias.

Verifica-se cenário semelhante na zona urbana de Giruá, e torna-se preocupante na medida em que se considera a degradação da função ambiental destas áreas mediante o avanço do crescimento urbano sobre as mesmas. A baixa porcentagem de APPs em desacordo com a legislação ambiental, possibilita condições para o município gerir e adequar suas APPs sem maiores danos ao meio ambiente, população, e custos para a administração pública. Contudo, é importante enfatizar que a expansão urbana é a maior responsável pelo uso irregular nas APPs (16,36\%). Esses resultados chamam a atenção para que os vetores de crescimento urbano respeitem os níveis de conservação da área.

Para Pereira et al. (2016), que avaliaram o uso e ocupação da terra das APPs segundo o Código Florestal e seus conflitos de uso, as classes de área urbana e áreas de uso agropecuário são as principais responsáveis pelo uso indevido da terra nas APPs.

Nunes et al. (2015) realizaram diagnóstico em quatro microbacias no Município de Alta Floresta/MT para diagnosticar o nível de degradação das APPs. Os autores verificaram que as APPs mais degradadas se localizavam próximas ao centro urbano, apresentando níveis entre 74 e $100 \%$ de degradação.

Em etapa complementar ao mapeamento do uso e cobertura da terra urbana com ênfase nas APPs, a análise de campo permitiu identificar e verificar os usos da terra ao longo dos cursos hídricos. Com relação a identificação das nascentes, nem todas foram localizadas, algumas passaram por processo de drenagem e o afloramento do curso d'água ocorre em áreas periféricas à mancha urbanizada, a exemplo da situação ilustrada na (Figura 4A). Esta nascente foi localizada com auxílio e informações de moradores, tendo em vista que encontra-se descaracterizada, e sob o local foi construída uma residência.

Nesse local, a execução da obra de drenagem não considerou a degradação ambiental da ação, tampouco os problemas de elevação do lençol freático, em períodos chuvosos, deixando o solo encharcado na área ocupada por populações. A implantação de infraestrutura urbana como loteamentos e construções causou o soterramento de nascentes em diversos pontos distribuídos na área de estudo. Séguim et al. (2006) afirmam que o desenvolvimento urbano em geral ignora os pequenos cursos d'água que cortam as cidades e, quando os gestores os notam, é para canalizá-los ou cobri-los com a justificativa da necessidade de mais espaço para ocupação e circulação. Azevedo e Oliveira (2014) destacam que a relação entre APPs e zonas urbanas nunca foi harmoniosa, sendo possível afirmar que esse fenômeno está presente na maior parte das cidades brasileiras. Isso se deve ao fato de que o código florestal anterior, Lei n $4.771 / 1965$, originalmente, não tutelava as zonas urbanas, mas disciplinava o uso e ocupação de espaços rurais. Portanto, originalmente, não era função do Código Florestal impor critérios e restrições ao uso e ocupação da terra em zonas urbanas. O uso e a ocupação da terra urbana era disciplinada por normas de natureza eminentemente urbanística, a exemplo da Lei nº 6.766/1979, que dispõe sobre o Parcelamento do Solo Urbano. A definição que as áreas urbanas deveriam respeitar os limites das APPs, foi instituída com a Lei nº 7.803/1989 que introduziu o

Figura 4 - Tipos de Uso da Terra nas APPs urbanas do município de Giruá/RS.

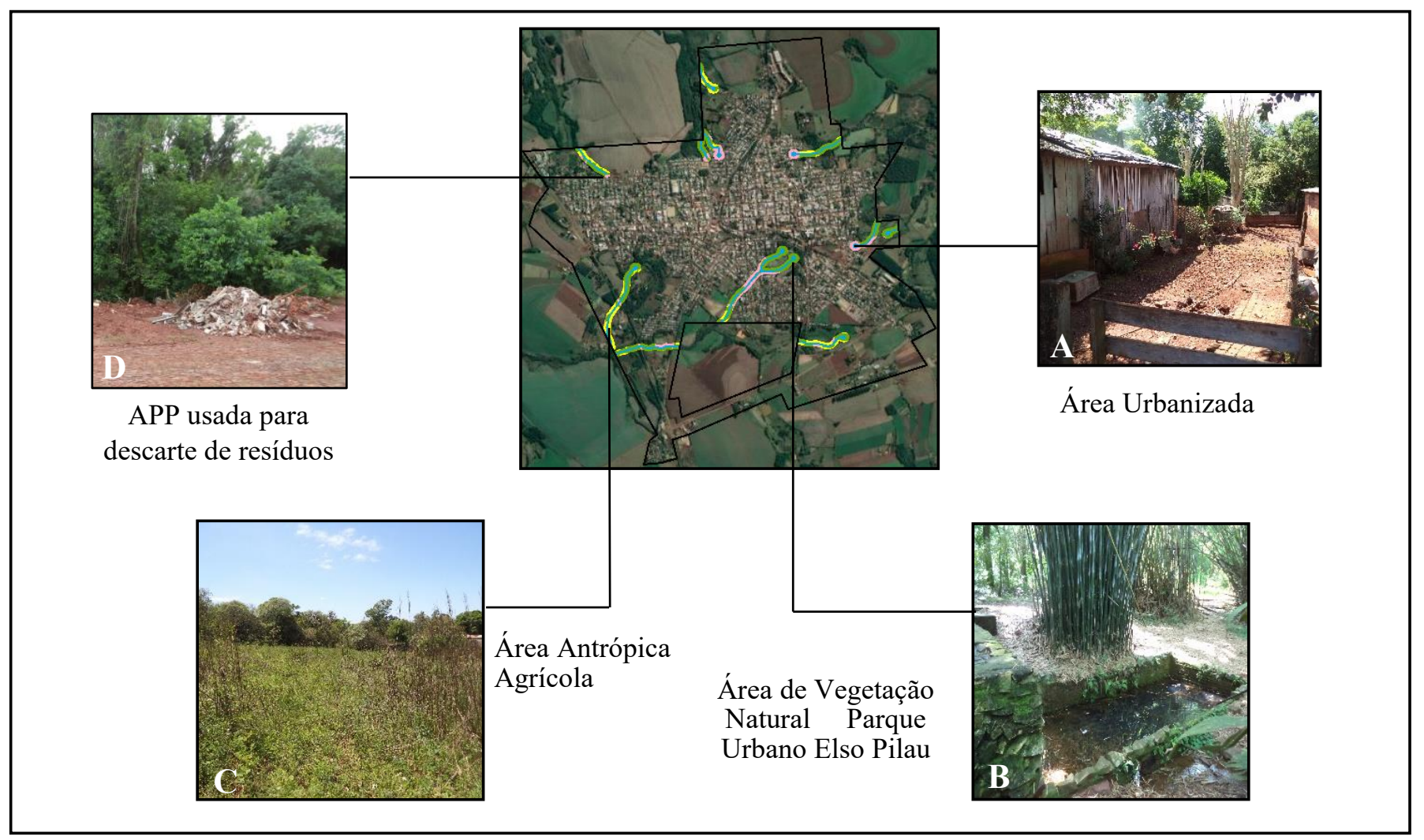


parágrafo único ao art. $2^{\circ}$ do código florestal em vigor no período, Lei no 4.771/1965, adiante transcrito: No caso de áreas urbanas, assim entendidas as compreendidas nos perímetros urbanos definidos por lei municipal, e nas regiões metropolitanas e aglomerações urbanas, em todo o território abrangido, observar-se-á o disposto nos respectivos planos diretores e leis de uso do solo, respeitados os princípios e limites a que se refere este artigo. Além disso, com a edição da Medida Provisória n ${ }^{\circ}$ 2.166/2001 e das Resoluções CONAMA 302/2002, 303/2002 e 369/2006, consolidou-se o entendimento de que o regime jurídico das APPs aplica-se às zonas urbanas.

Nesse panorama, surgiram muitos conflitos devido as ocupações e usos já consolidados nas APPs de zonas urbanas, conflitos que perduram e aumentam continuamente, visto que a aplicação de políticas públicas, capazes de promover o ordenamento do uso da terra urbana, não acompanhou a velocidade do processo de urbanização das cidades brasileiras.

Como podemos constatar na Figura 4D, as APPs ainda são vistas como áreas sem utilidade, usadas para descartes de resíduos. Esse descaso por parte da população é refletido na gestão pública que frequentemente não considera a importância dessas áreas no tocante a valorização da paisagem, conservação dos recursos hídricos e melhoria da qualidade de vida da população. As áreas urbanas têm grande impacto nas APPs, não apenas pela retirada de vegetação em áreas sensíveis e impermeabilização do solo mas também como fonte de contaminação pontual e liberação de resíduos nos canais de água, afetando sua qualidade (GONÇALVES et al., 2005).

Vargas e Nascimento (2010) ressaltam que o poder público tem sua parcela de responsabilidade na geração de impactos e conflitos em APPs, devido sua postura de tolerância a ocupação dessas áreas, se por um lado proteger as APPs segundo a legislação poderia significar a retirada dos ocupantes irregulares, criando uma exclusão social evidente, de outra forma proteger socialmente os ocupante irregulares com ações que prejudiquem o meio ambiente não seria a forma ideal de gerir essas áreas. A vista disso como conciliar esses interesses, considerando que a maior parte da rede urbana brasileira apresenta ocupações e usos irregulares em APPs?

A solução para os problemas decorrentes da ocupação de APPs divide opiniões, uma vez que o direito à propriedade e ao meio ambiente equilibrado são todos constitucionais e compatibilizar esses direitos torna-se tarefa difícil tanto no plano jurídico quanto nas questões sociais das pessoas que residem nesses locais (VARGAS; NASCIMENTO, 2010).

Nesse sentido o desenvolvimento das cidades deve estar baseado nas diretrizes do Estatuto da Cidades Lei Federal 10.257 de julho de 2001, que estabelece as normas de ordem pública e interesse social que regulam o uso da propriedade urbana em prol do bem coletivo, da segurança e do bem-estar dos cidadãos, bem como do equilíbrio ambiental. De acordo com o Art. 2 do Estatuto das Cidades é garantido o direito a cidades sustentáveis, entendido como o direito à terra urbana, à moradia, ao saneamento ambiental, à infraestrutura urbana, trans- porte, aos serviços públicos, trabalho e ao lazer, para as presentes e futuras gerações, mediante o planejamento do desenvolvimento das cidades, da distribuição espacial da população e das atividades econômicas do Município e do território sob sua área de influência, de modo a evitar e corrigir a poluição e degradação ambiental, as distorções do crescimento urbano e seus efeitos negativos sobre o meio ambiente.

Para o urbanista Edésio Fernandes a busca por soluções de conflitos ambientais não deve permanecer presa a situações extremas, mas deve-se desenvolver programas locais que busquem a conjunção desses direitos e interesses, barrando novas ocupações, promovendo remoções em certas áreas, bem como reflorestamento e plantio, entre outras medidas mitigadoras e compensatórias (FERNANDES, 2001).

No sentido de promover a melhoria das condições ambientais, diversas áreas usadas como lavoura, entre outros usos, encontram-se atualmente em processo de regeneração natural como é o caso do Parque Urbano Elso Pilau, (Figura 4B), que era área de lavoura e foi transformada em parque no ano de 1989, embora nem toda a extensão das APPs tenha sido recuperada adequadamente com espécies nativas de mata ciliar, destaca-se como uma ação que busca restabelecer as características naturais que preservem os recursos hídricos, a biodiversidade e promova o bem estar da população.

Outro uso frequente das APPs é por atividades antrópicas agrícolas, principalmente em municípios de regiões interioranas, como é o caso de Giruá. A Figura 4C apresenta exemplo de APP usada para fins agropecuários, constatou-se que o uso para pastagem e criação de animais, mesmo em meio urbano, é a principal finalidade das áreas antrópicas agrícolas urbanas. Segundo Balsan (2006) a ocupação das APPs por atividades antrópicas agrícolas pode causar muitos problemas ao meio ambiente, além do desmatamento, o aumento do risco de erosão, perda gradual da fertilidade do solo, ameaça dos recursos hídricos da região promove o assoreamento dos cursos d'água, podendo haver contaminação por produtos químico, fertilizantes e pesticidas usados na agricultura.

Considerando a necessidade de medidas de controle e prevenção para recuperar as áreas que não estão de acordo com a legislação ambiental, Louzada (2009) recomenda algumas ações com vista a melhoria da qualidade ambiental, a saber:

- Recuperação vegetal com práticas de reflorestamento;

- Fiscalização mais efetiva dos órgãos ambientais, com o intuito de prevenir ocupação e uso irregular da terra;

- Criação de um sistema que possa fornecer informações relevantes à implantação de projetos de uso e cobertura da terra, proteção e conservação ambiental do município.

O Art. 75 do Plano Diretor de Giruá, dispõe que nas áreas que margeiam os córregos, rios, nascentes e lagos, em área urbana ou rural, é obrigatório a recomposição com espécies nativas específicas das matas ciliares regionais. Destaca-se que o reflorestamento da mata ciliar e da cabeceira de drenagens, em áreas urbanas e rurais, está elencado entre os programas prioritários da 
Política Municipal de Meio Ambiente de Giruá (GIRUÁ, 2013). Cocco et al. (2016) destacam a necessidade do desenvolvimento de planos de ação para vigilância da ocupação em APPs, bem como políticas públicas para promover a educação e gestão ambiental, envolvendo os agentes públicos, sociedade, produtores rurais e demais interessados e responsáveis pela construção do desenvolvimento sustentável.

Os resultados indicam que as APPs urbanas sofrem pressões ambientais que podem impactar nos recursos hídricos. Embora a zona urbana não apresente rios com fluxos de grande vazão, sua preservação é tão necessária quanto a preservação de grandes rios, pois tratam-se de nascentes e início de redes de drenagem. Desta forma, determinadas atividades podem ter ações pontuais, mas com impactos que se estendem ao longo da rede hidrográfica.

\section{Conclusão}

Conforme análise dos mapas elaborados, a cobertura principal da terra na zona urbana de Giruá, refere-se a áreas urbanizadas, seguida pelas áreas antrópicas agrícolas e áreas de vegetação natural. Pode-se verificar que as APPs estabelecidas pela legislação, se implementadas, ocupariam $4,36 \%$, correspondendo a 37,35 ha do território urbano. Verificou-se também que as APPs urbanas apresentam uso conflitivo da terra, sendo as áreas urbanizadas com maior representação no uso irregular, com $16,36 \%$ do território. Contudo a maior parte das APPs encontra-se de acordo com a legislação.

Este estudo demonstra, que embora a maioria das APPs na área urbana de Giruá/RS estão de acordo com a legislação é necessário assegurar a manutenção das nascentes e cursos d'água, garantindo sua preservação.

O uso do SIG permitiu que fossem mapeados os limites das APPs urbanas do município de Giruá/RS, e a metodologia empregada pode ser aplicada em todo território do município de Giruá, considerando que a abordagem na zona rural necessita de informações sobre dimensões das propriedades rurais, variável necessária para adequada delimitação das APPs em estabelecimentos agropecuários.

A adoção do mapeamento das APPs poderá contribuir para minimizar os conflitos de uso da terra e evitar a degradação dos fragmentos florestais remanescentes uma vez que essas informações podem subsidiar o plano diretor e auxiliar a implantação de medidas fiscalizatórias com o intuito de impedir a ocupação de novas áreas protegidas, bem como servir de base para a elaboração de projetos que visem a recuperação das áreas ocupadas de forma irregular.

Os dados gerados na elaboração do presente trabalho foram disponibilizados à administração pública municipal de Giruá/RS no formato de mapas e arquivos "shapefile" para que o município possa adotar ações de recuperação das áreas em conflitos.

Por fim, recomenda-se que o levantamento da cobertura e do uso da terra seja periodicamente atualizado, com a finalidade de representar a dinâmica da ocupação urbana, além de fornecer dados atualizados.

\section{Referências}

ANDRADE, R. R., BARBOSA, L. P. Áreas consideradas de preservação permanente de reservatórios d'água artificiais e ao redor de lagoas e lagos naturais. Competência legislativa suplementar municipal: abrangência e limites sob a ótica do direito ambiental e urbanístico. Revista de Direito Ambiental, v. 46, p. 146 - 163, 2007.

AZEVEDO, R. E. S., OLIVEIRA, V. P. V. Reflexos do novo Código Florestal nas Áreas de Preservação Permanente - APPs - urbanas. Desenvolvimento e Meio Ambiente (UFPR), v. 29, p. 71-91, 2014.

BALSAN, R. Impactos decorrentes da modernização da agricultura brasileira. Revista de Geografia Agrária v.1, p. 123-151, 2006.

BRASIL, Constituição da República Federativa do Brasil, de 5 de outubro de 1988 .

BRASIL. Lei n⿳0 7.803, de 18 de julho de 1989. Altera a redação da Lei no 4.771, de 15 de setembro de 1965, e revoga as Leis n. ${ }^{\circ} 6.535$, de 15 de junho de 1978, e 7.511, de 7 de julho de 1986. Diário Oficial da União, 20 julho 1989.

BRASIL. Lei ${ }^{\circ}$. 10.257, de 10 de julho de 2001, Estatuto das Cidades. Diário Oficial da União, 11 julho 2001.

BRASIL. Lei ${ }^{\circ}$. 12.651, de 25 de maio de 2012, Código Florestal. Diário Oficial da União, 25 maio 2012.

BORGES, L. A. C., REZENDE, J. L. P., PEREIRA, J. A. A., JÚNIOR, L. M. C., BARROS, D. A. Áreas de preservação permanente na legislação ambiental brasileira. Ciência Rural, Santa Maria, v.41, n.7, p.1202-1210, jul., 2011.

BRESSANE, A., MOCHIZUKI, P. S., ROVEDA, J. A. F., SALVADOR, N. N. B. Sistema de apoio à Gestão de Áreas Verdes na Preservação Permanente de Corpos Hídricos Urbanos. http://dx.doi.org/10.5902/198050987550, v. 26, p. 957, 2016.

CAIXETA, D. M. Mapeamento, Identificação e Monitoramento das Áreas de Proteção Permanente ao longo do Ribeirão Anicuns no Município de Goiânia/ GO. Anais XIV Simpósio Brasileiro de Sensoriamento Remoto; 2009 abril 25-30 Natal, Brasil. p. 617-622.

CÂMARA, G. Sistemas de Informação Geográfica para Aplicações Ambientais e Cadastrais: Uma Visão Geral. In: Moacir de Souza e Silva. (Org.). Cartografia, Sensoriamento e Geoprocessamento. 1a.ed. Lavras: Universidade Federal de Lavras - UFLA, 1998, v. único, p. 59-88.

Conselho Nacional do Meio Ambiente - CONAMA. Resolução n.․ 302, de 20 de março de 2002. Dispõe sobre os parâmetros, definições e limites de Áreas de Preservação Permanente de reservatórios artificiais e o regime de uso do entorno. Brasília: Diário Oficial da União, 13 maio 2002. 
Conselho Nacional do Meio Ambiente. Resolução n.303, de 20 de março de 2002. Dispõe sobre parâmetros, definições e limites de Áreas de Preservação Permanente. Brasília: Diário Oficial da União, 13 maio 2002.

Conselho Nacional do Meio Ambiente. Resolução n.․ 369, de 28 de março de 2006. Dispõe sobre os casos excepcionais, de utilidade pública, interesse social ou baixo impacto ambiental, que possibilitam a intervenção ou supressão de vegetação em Área de Preservação Permanente-APP. Brasília: Diário Oficial da União, 29 março 2006.

CARDOSO, J. A., AQUINO, C. M. S. Mapeamento dos conflitos de uso nas Áreas de Preservação Permanente (APPs) da microbacia do riacho do Roncador, Timon (MA). ISSN: 19848501 - A2. Boletim Goiano de Geografia (Online), v. 33, p. 133-148, 2013.

CAMPOS, F. F., MATIAS, L. F. Mapeamento das Áreas de Preservação Permanente (APPs) e sua Situação de Uso e Ocupação no Município de Paulínia (SP). Geociências (São Paulo. Online), v. 31, p. 309-319, 2012.

COCCO, J., GALVANin, E. A. S., RIBEIRO, H. V., NASCIMENTO, D. L. Land use/land cover analysis in the Permanent Preservation Areas at the springs of the sub-basin from Mato Grosso State-Brazil. Ciência e Natura, v. 38, p. 1411-1418, 2016.

EUGENIO, F. C., SANTOS, A. R., LOUZADA, F. L. R. O., MOULIN, J. V. Confronto do uso e cobertura da terra em áreas de preservação permanente da bacia hidrográfica do rio alegre no município de Alegre, Espírito Santo. Engenharia Ambiental v. 7, p. 110-126, 2010.

EMBRAPA, Empresa Brasileira de Pesquisa Agropecuária. Identificação, mapeamento e quantificação das áreas urbanas do Brasil. Campinas: Embrapa Gestão Territorial, 2017 (Comunicado Técnico).

FERNANDE, E. Direito Urbanístico e política urbana no Brasil. Belo Horizonte: Del Rey, 2001.

GASPARINI, K. A. C., LYRA, G. B., FRANCELINO, M. R., DELGADO, R. C., OLIVEIRA JUNIOR, J. F., FACCO, A. G. Técnicas de Geoprocessamento e Sensoriamento Remoto Aplicadas na Identificação de Conflitos do Uso da Terra em Seropédica-RJ. Floresta e Ambiente, v. 20, p. 296-306, 2013.

Giruá. Lei S/N, de 03 de abril de 1990, Lei Orgânica.

Giruá. Lei ${ }^{\circ} 4.951$, de 18 de novembro de 2013, Plano Diretor.

Giruá. Lei ${ }^{\circ} 4.953$, de 18 de novembro de 2013, Plano de Desenvolvimento Físico Urbano.

Giruá. Lei $N^{\circ} 4.954$, de 18 de novembro de 2013, Parcelamento do Solo Urbano.
GONÇALVES, C. S., RHEINHEIMER, D. S., PELLEGRINI, J. B. R., KIRST, S. L. Qualidade da água numa microbacia hidrográfica de cabeceira situada em região produtora de fumo. Revista Brasileira de Engenharia Agrícola e Ambiental, v.9, p.391- 399, 2005.

INSTITUTO BRASILEIRO DE GEOGRAFIA E ESTATÍSTICA [Internet]. Brasília: Ministério do Planejamento, Orçamento e Gestão (BR) Acessado em 25 de maio de 2018. Disponível em: https://cidades.ibge. gov.br/brasil/rs/girua/panorama.

INSTITUTO BRASILEIRO DE GEOGRAFIA E ESTATÍSTICA, Manual Técnico de Uso da Terra. Rio de Janeiro. 2013. 171 p. Acessado em: 23 maio. 2018. Disponível em: https://biblioteca.ibge.gov.br/visualizacao/ livros/liv81615.pdf.

INSTITUTO NACIONAL DE PESQUISAS ESPACIAIS [Internet]. Acessado em 22 de março de 2018. Disponível em: https://inpe.gov.br.

LOUZADA, F. L. R. O., SANTOS, A. R., MARINHO, C. C., SATLER, M. A. Delimitação automática das áreas de preservação permanentes da bacia hidrográfica do ribeirão Estrela do Norte, ES. In: Anais do IX Encontro Latino Americano de Pós-Graduação - EPG. Ciência e Tecnologia: o paradigma do século XXI; 2009; São José dos Campos, SP. São José dos Campos: UNIVAP; 2009.

MACHADO, P. A. L. Direito Ambiental Brasileiro. 14. ed. São Paulo: Malheiros Editores, 2006. v. 1. 1094p.

MACEDO, S. S. Os sistemas de espaços livres e a constituição da esfera pública contemporânea no Brasil: relatório final de Projeto Temático de Pesquisa. São Paulo: FAPESP, 2011.

MENSAH, J. H. R., LIMA, R. H. S., PONS, N. A. D. Mapeamento das Áreas de Preservação Permanentes (APPs) na bacia hidrográfica do Ribeirão do Rosário em Delfim Moreira (MG): um subsídio à preservação Ambiental. Revista Brasileira de Energia Renováveis, v. 7, p. 441-451, 2018.

MOREIRA, A. M., SANTOS, R. F., FIDALGO, E. C. C. Planejamento Ambiental de Áreas Verdes: Estudo de Caso em Campinas-SP. Rev. Inst. Flor., v.19, n.1, p. 19-30, 2007.

NUNES, E. J. S., SILVA, E. P., SOUZA, E., ROCHA FILHO, J. A., SILVA, D. S. N. Geotecnologias no diagnóstico de conflitos de uso do solo de uma microbacia do município de Alta Floresta/MT. Ciência Florestal (UFSM. Impresso) v. 25, p. 689-697, 2015.

OLIVEIRA, M. J. Proposta metodológica para delimitação automática da Áreas de Preservação Permanente em topos de moro e em linha de cumeada. 2002. 53p. Dissertação (Mestrado em Ciência Florestal) - Universidade Federal de Viçosa, Viçosa, 2002. 
OSCO, L. P., BEZERRA, J. P. P., GONCALVES, D. L., LEAL, A. C., RAMOS, A. P. M., ARANA, A. R. A. Mapeamento de Áreas de Preservação Permanente no manancial do alto curso do rio Santo Anastácio - Pontal do Paranapanema estado de São Paulo. In: ENEPE - Encontro Nacional de Ensino, Pesquisa e Extensão, 2016, Presidente Prudente. Colloquium Exactarum, 2016. v. 8. p. 50-58.

PEluZiO, T. M. O., SANTOS A. R., FIELDLER N. C. Mapeamento de áreas de preservação permanente no ArcGIS $^{\circledR}$ 9.3. Alegre: CAUFES; 2010. p. 58.

PEREIRA, B. W. F., MACIEL, M. N. M., OLIVEIRA, F. A., SILVA ALVES. M. A. M., RIBEIRO, A. M., FERREIRA, B. M., RIBEIRO, E. G. P. Land use and water quality degradation in the Peixe-Boi River watershed. Revista Ambiente \& Água, v. 11, p. 472-485, 2016.

PINTO, C. E. T., ROSSETE, A. N. Mapeamento dos conflitos no uso da terra em áreas de preservação permanente na microbacia hidrográfica do Córrego Capitão Décio, Nova Xavantina-MT. Ciência e Natura, v. 34, p.139-155, 2013.

POLLO, R. A., BARROS, Z. X., GARCIA, Y. M., SILVEIRA, G. R. P., BARROS, B. S. X., CAMPOS, M. Utilização de Imagem de Satélite Landsat no Mapeamento da Ocupação da Terra e seus Conflitos de Uso em APPs na Bacia Hidrográfica do Ribeirão Paraíso-São Manuel (SP). Irriga (UNESP. CD-ROM), v. 19, p. 478, 2014.

REIS. L. C., REIS T. E. S., ABI SAAB O. J. G. Diagnóstico das áreas de preservação permanente das microbacias hidrográficas do município de Bandeirantes - Paraná Semina: Ciências Agrárias, Londrina, v. 30, n. 3, p. 527536, jul./set. 2009.

SÉGUiM, E., KLIGERMAN, D. C., ASSUMPÇÃO, R. F. Uma Gestão Sustentável das Águas Urbanas e a Aplicabilidade do Princípio da Precaução - como convive a população urbana e seus rios. Revista de Direitos Difusos, São Paulo, v. 7, n. 39, p. 69-84, set./out. 2006.

SEPE, P. M., PEREIRA, H. M. S. B., BELLENZANI, M. L. O novo Código Florestal e sua aplicação em áreas urbanas: uma tentativa de superação de conflitos? $3^{\circ}$

Seminário Nacional sobre o Tratamento de Áreas de Preservação Permanente em Meio Urbano e Restrições Ambientais ao Parcelamento do Solo. Belém - PA, 2014.

SOARES, J. F. Análise orientada a objeto de imagens de satélite para mapeamento de áreas de preservação em reservatório hidrelétrico. 2015. 82p. Dissertação (Mestrado em Engenharia Agrícola) - Universidade Federal de Lavras, Lavras, 2015.

VARGAS, H. L., NASCIMENTO, E. P. O dilema das ocupações irregulares em Áreas de Preservação Permanente. O caso de Feira de Santana, BA. Revista de Políticas Públicas, v. 14, p. 347-356, 2010. 